Running head: MENTALLY DISORDERED FIRESETTER RISK

Revised Article Word Count 4998 (excluding title, abstract, references, tables)

Citation: Wyatt, B., Gannon, T. A., McEwan, T., Lockerbie, L., \& O’ Connor, A. (in press). Mentally disordered firesetters: An examination of risk factors. Psychiatry: Interpersonal and Biological Processes.

Note - this article may vary slightly from the corrected and proofed published version.

\title{
Mentally Disordered Firesetters: An Examination of Risk Factors
}

Becky Wyatt $^{\mathrm{ab}}$, Theresa A. Gannon ${ }^{\mathrm{ab}}$, Troy E. McEwan ${ }^{\mathrm{c}}$, Lona Lockerbie ${ }^{\mathrm{ba}}$ and Alisha O'

$$
\text { Connor }{ }^{\mathrm{ab}}
$$

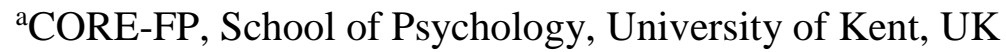

${ }^{\mathrm{b}}$ Kent Forensic and Specialist Care Group, KMPT, UK

${ }^{\mathrm{c} C e n t r e}$ for Forensic Behavioural Science, Swinburne University of Technology and

Forensicare, Australia

Author Note

Becky Wyatt, CORE-FP, School of Psychology, University of Kent and Kent Forensic and

Specialist Care Group, KMPT, UK; Theresa A. Gannon, CORE-FP, School of Psychology,

University of Kent and Kent Forensic and Specialist Care Group, KMPT, UK; Troy

McEwan, Centre for Forensic Behavioural Science, Swinburne University of Technology and Forensicare, Australia; Lona Lockerbie, Kent Forensic and Specialist Care Group, KMPT and CORE-FP, School of Psychology, University of Kent, UK; and Alisha O’ Connor, CORE-FP, School of Psychology, University of Kent and Kent Forensic and Specialist Care Group, KMPT, UK.

We would like to thank Dr Nichola Tyler for her helpful comments on an earlier draft of this manuscript. Correspondence should be addressed to Theresa A. Gannon, School of Psychology, Keynes College, University of Kent, Canterbury, Kent, CT2 
Running head: MENTALLY DISORDERED FIRESETTER RISK

\begin{abstract}
Objective: In this study, we examined the risk-related characteristics of mentally disordered patients who had either been (1) involved in a firesetting incident, or (2) involved in a nonfiresetting comparison incident whilst under the care of the National Health Service. Method: One hundred and thirty-two participants were recruited within an NHS Care Group in England (66 mentally disordered firesetters, 66 mentally disordered comparisons). Logistic regression was used to model the ability of static, dynamic, and incident-related factors in predicting whether or not a patient had set a fire (including gender-sensitive sub-analyses), and whether a patient firesetter was male or female, or a one-time or repeat firesetter. Results: We identified a cluster of variables that predicted firesetting status. We also identified key factors that predicted female patient firesetters relative to female patient controls who engaged in other undesirable behaviours and male patient firesetters. A cluster of variables predictive of repeat versus one-time firesetting also emerged. Conclusions: Findings are discussed in relation to further development of risk-related firesetting theory.
\end{abstract}

Key Words: mental disorder, firesetting, risk, forensic mental health, National Health Service 
Running head: MENTALLY DISORDERED FIRESETTER RISK

\section{Mentally Disordered Firesetters: An Examination of Risk Factors}

Approximately $10 \%$ of patients in secure mental health institutions hold a conviction for deliberate firesetting (Dickens \& Doyle, 2016). Yet, there is no specialised risk assessment to aid professionals in risk management decisions with these individuals. Instead, many professionals rely on violence risk assessments to bridge the gap (Historical Risk Clinical-20 V3, Douglas, Hart, Webster, \& Belfrage, 2013). However, deliberate firesetting often

originates from non-violent motivators (Gannon, Ó Ciardha, Doley, \& Alleyne, 2012). Thus, violence risk assessments are unsuitable for widespread use with firesetters (McEwan, Doley, \& Dolan, 2012).

\section{Risk Assessment}

The most 'practically useful' (Brown, Bowen, \& Prescott, 2017) method of forensic risk assessment combines historical, unchangeable static risk factors (such as criminal history) with fluctuating - yet treatable — dynamic risk factors (e.g., relationship problems or hostility). These risk factors are brought together using structured professional judgement to form an understanding about the relative likelihood of particular types of future behaviour (e.g., future violence, firesetting) and of what may contribute to a 'risk formulation' (Hart, Sturmey, Logan, \& McMurran, 2011).

\section{Theoretical and Research Indicators of Firesetting Risk}

For years, no comprehensive theory was available to explain why adults with or without a mental disorder misuse fire. In 2012, Gannon and colleagues developed the MultiTrajectory Theory of Adult Firesetting (or M-TAFF). Gannon et al. propose that individuals begin to misuse fire due to dynamic risk factors spanning four areas: Fire Factors (i.e., cognitive and emotional responses to fire), Attitudes (i.e., antisocial attitudes), Social Effectiveness (i.e., poor social skills, social isolation), and Coping and Control (i.e., emotion regulation problems, poor impulse control). Few gender differences are alluded to although 
Running head: MENTALLY DISORDERED FIRESETTER RISK

women are hypothesised to have impulsivity problems that result in 'cry for help', self-harm, or suicide fire misuse. Static risk factors are largely ignored and there is no focus on how firesetting characteristics (e.g., premeditation) might be associated with gender or firesetting maintenance.

\section{Static risk and incident-related characteristics}

Research examining risk in mentally disordered firesetters (MDFs) is scant. Studies suggest that male dominated samples of MDFs are characterised by negative developmental histories and higher prevalences of personality disorder diagnoses relative to non-firesetter mentally disordered offenders (Bradford, 1982; Hagenauw, Karsten, Akkerman-Bouwsema, de Jager \& Lancel, 2014; Räsänen, Hakko \& Väisänen, 1995). MDFs are also characterised by higher numbers of previous mental health service contacts/admissions (Ducat, Ogloff, \& McEwan, 2013; Geller, Fisher, \& Moynihan, 1992). When female MDFs have been examined, some differences have been reported. Dickens and colleagues (2007) found that female MDFs, relative to male MDFs, were more likely to have experienced past relationship difficulties, but less likely to have alcohol problems. Female MDFs were also less likely to have been intoxicated during their firesetting, and were more likely to set fires to attract attention or as 'parasuicide'. Enayati, Grann, Lubbe, and Fazel (2008) compared the psychiatric diagnoses of male and female MDFs in Sweden and found no distinctive gender patterns. More recently, however, Ducat, McEwan, and Ogloff (2017) reported that female firesetters in contact with the criminal justice system are more often diagnosed with disorders such as borderline personality disorder and substance misuse, relative to male firesetters.

\section{Dynamic risk factors}

Research has found that when compared to other mentally disordered offending groups, groups of male or mostly male MDFs are characterised by increased hostility 
Running head: MENTALLY DISORDERED FIRESETTER RISK

(Hagenauw et al., 2014; Rice \& Harris, 1991), and alcohol misuse (Enayati et al., 2008;

Labree, Mijman, van Marle, \& Rassin, 2010; Räsänen et al., 1995). Additionally, active mental illness and social skills issues appear common (Bradford, 1982; Hagenauw et al., 2014; Räsänen et al, 1995).

Recent research suggests that male imprisoned firesetters - many of whom have mental health difficulties - self-report greater problems in their cognitive and emotional responses to fire (e.g., finding serious fires exciting) relative to matched non-firesetting offenders (Gannon et al., 2013). Dynamic risk factors common to mainstream offenders such as emotional-regulation problems (Craig, Dixon, \& Gannon, 2013) have also been identified in male imprisoned firesetters (Gannon et al., 2013). Other work suggests female MDFs are characterised by impulsivity (Long, Fitzgerald, \& Hollin, 2015) and emotion-regulation deficits that promote self-harm/suicide (Miller \& Fritizon, 2007). Nevertheless, one study (see Tyler, Gannon, Dickens, \& Lockerbie, 2015) comparing mostly male MDFs with mentally disordered non-firesetting offenders has shown that while MDFs have a more problematic emotional response to fire, other differentiating dynamic risk factors could not be identified.

\section{Repeat firesetting}

Very little is known about risk factors associated with repeat firesetting. Rice and Harris (1996) found that young age at first fire, low intelligence, and lack of aggression predicted repeat firesetting for male MDFs. Repeat MDFs also appear to have more convictions and have spent a greater time in prison relative to non-firesetting mentally disordered offenders (Dickens et al., 2009; Repo, Virkkunen, Rawlings, \& Linnoila, 1997). Unsurprisingly, then, antisocial personality disorder appears predictive of repeat mentally disordered firesetting (Repo et al., 1997). Dynamic risk factors such as active symptoms of mental illness (particularly psychosis) also appear common amongst repeat MDFs relative to 
Running head: MENTALLY DISORDERED FIRESETTER RISK

one-time MDFs (Dickens et al., 2009; Repo et al., 1997). More recently, Tyler et al. (2015)

found that MDFs exhibiting fire interest were most likely to have perpetrated multiple episodes of firesetting.

\section{The Current Research}

A key reason why understanding of MDFs remains limited is poor study design.

Studies use male dominated samples and do not use control groups of other mentally disordered individuals who are meaningfully matched on key characteristics. Furthermore, few studies adequately compare female and male $\mathrm{MDFs}^{1}$ or one-time and repeat firesetters. In this study, we draw upon specialist archived National Health Service (NHS) patient data files $(N=132)$ to identify the static, dynamic, and incident-related risk predictors for firesetting in mentally disordered individuals. Important questions key to developing empirically-based models of mentally disordered firesetting risk remain unanswered. These questions revolve around (a) whether predictors of firesetting are different to predictors of other undesirable behaviours, (b) whether male and female firesetting is characterised by different predictors, and (c) whether there are discernable risk factors for engaging in repetitive firesetting relative to one-time firesetting.

The data set is novel since it will allow us to match and compare mentally disordered individuals who have set fires during their time as an NHS patient with mentally disordered individuals who have never set a fire but who have perpetrated another undesirable incident whilst under NHS care. First, we compare the static, dynamic, and incident related risk factors associated with the firesetting or control incident to examine whether there are characteristics that differentiate MDFs from MDCs (including sub-analyses by gender).

\footnotetext{
${ }^{1}$ Although Ducat et al.'s (2017) recent published paper compares firesetters on characteristics of psychopathology, it does not specifically examine MDFs.
} 
Running head: MENTALLY DISORDERED FIRESETTER RISK

Then, we focus on the MDF group, examining whether static, dynamic, and incident-related characteristics differentiate male and female MDFs or one-time versus repeat MDFs.

\section{Method}

\section{Design}

This study was conducted according to APA ethical guidelines and was approved by the University's Research Ethics Committee (Ref: 20143546), London Fulham NHS REC (Ref: 14/LO/1060) and the NHS Confidentiality Advisory Group (14/CAG/1005). The study design was retrospective and involved pre-existing trust incident report forms from 3 January 2005 - 24 June 2014 to identify participants who had been either been (a) involved in a firesetting incident, or (b) involved in a non-firesetting comparison incident (e.g., drug taking, self-harm, violence).

\section{Participants}

One hundred and thirty-two participants were recruited within an English NHS Care Group (66 MDFs, 66 MDCs). Approval was sought under Regulation 5 of the Health Service (Control of Patient Information) Regulations 2002 to process patient identifiable information without prior informed consent. This regulation could be used since all patients admitted to trust care are provided with documentation informing them that their details will be used for research purposes unless they opt out.

MDFs. To be classified as a MDF, individuals needed to be: (1) under trust care for a psychiatric problem, and (2) the named perpetrator of a deliberate incident of firesetting with a trust incident form for the period 3 January 2005 to 24 June 2014. Participants' ages ranged from 18-71 years $(M=41.7$ years, $S D=15.1)$ at the time of their firesetting and the majority identified themselves as White British $(93.9 \%, n=62)$. Overall, 60.6\% $(n=40)$ were females 
Running head: MENTALLY DISORDERED FIRESETTER RISK

and the mean age of male and female MDFs was similar $(M \mathrm{~s}=40.8$ years and 42.2 years respectively). Patients were distributed across inpatient/community services. Most were inpatients within a mental health unit ${ }^{2}$ when the firesetting took place $(71.2 \%, n=47)$. The remainder were acute community mental health patients (i.e., early community intervention and crisis resolution; 28.8\%, $n=19$ ). MDFs were classified as repeat firesetters if their file records showed multiple incidents of intentional firesetting (regardless of formal convictions).

MDCs. The matched MDCs were: (1) under trust care for a psychiatric problem, and (2) the named perpetrator of a non-firesetting incident recorded within a trust incident form for the period 3 January 2005 to 24 June 2014. Incidents included violence, sexual abuse, absconsion, self-harm and drug taking. All available documentation was reviewed to ensure, as far as was possible, that MDCs did not have a history of firesetting. MDCs were matched to MDFs on gender, age (+/- five years), as well as inpatient/community service that the incident occurred within.

\section{Procedure and Materials}

First, pre-existing trust incident report forms were requested and reviewed by the first author electronically or in paper format. Each patient's case file differed regarding the number of records/reports within it and very few contained psychometric assessments. If the first author felt that a case file did not provide sufficient information for coding (e.g., if there was no documentation covering the month leading up to the index incident), then the file was replaced with a new patient case file until enough files with sufficient information where available for coding. MDFs' files were reviewed first so that a corresponding MDC file could be matched. Second, following a literature review, a basic checklist of characteristics was devised encompassing static, dynamic, and incident-related characteristics. File information

\footnotetext{
${ }^{2}$ This did not include prison healthcare.
} 
Running head: MENTALLY DISORDERED FIRESETTER RISK

reviewed included risk assessments, Mental Health Review Tribunal reports, psychological assessments, and nursing progress notes. Using the checklist, the first author determined whether each checklist factor was present using each patient's case file. In the case of dynamic risk, factors needed to be present in the month prior to the incident (firesetting or control) in order to be rated as present. For repeat firesetters, if multiple incidents of firesetting were apparent then the first incident was chosen for the coding of dynamic and incident risk factors. The checklist evolved substantially throughout the review. To promote the discovery of previously unrecorded dynamic risk factors, potentially risk-increasing characteristics found within the patient files were documented. Then, upon completion of the file reviews, all items were reviewed and collapsed as appropriate (e.g., 'poor sleep hygiene' and 'poor diet', were combined into a broader item of 'poor self-care'3).

Variables. Basic static (e.g., previous hospital admission), dynamic (e.g., change in care plan), and incident factors (e.g., premeditation) were recorded for each participant (see Tables 3 for the full list of variables). All dynamic risk factors were recorded as present or absent in the month prior to the firesetting or control incident. For example, the statement "Patient became verbally aggressive and hostile, demanding medication" was coded as the dynamic factor of hostility and "Phone call received from daughter stating that mother was going to commit suicide" was coded as the dynamic factor of suicidal ideation/self-harm. Only one statement such as those described above was required within each case file to provide evidence of each static, dynamic, or incident characteristic.

Coding. The first author collected and coded all files. To reduce possible bias, a second independent researcher-experienced in working with mentally disordered offenders-

\footnotetext{
${ }^{3}$ We set up the original checklist to obtain information on fire interest, passive personality, and confrontation avoidance. However, these variables had to be removed from the checklist because of difficulty ascertaining their presence/absence from file review data alone.
} 
Running head: MENTALLY DISORDERED FIRESETTER RISK

independently coded a randomly selected $20 \%$ of the patient files $(n=28 ; 14$ MDFs, 14

MDCs). The two coders demonstrated a $100 \%$ concordance rate, whereby both had

independently noted the same codes for all double coded files. The first author spent several hours training the coder using examples which may explain this exceptional concordance.

\section{Data Analysis Strategy}

Analyses were conducted using IBM SPSS statistics 24.0. Exploratory analyses were conducted using Pearson's $\chi^{2}$ analyses (with Fisher's Exact test where expected cell sizes < 5). We did not correct for error regarding the number of univariate tests undertaken due to the novelty of the research questions and desire to ensure all potential risk factors were considered for model inclusion. Single step binary logistic regression was used to evaluate the combined predictive power of all significant univariate predictors, with all predictors assessed a priori for multicollinearity. Models were built iteratively such that variables were removed with reference to the Wald statistic, change in -2loglikelihood value, and the overall rate of correct classification. The aim of this process was to achieve the most parsimonious model with the best classification of cases. Outliers and influential cases were examined and reported for each final model. Logistic regression differentiation between target groups was assessed using the proportion of the sample correctly classified and the Receiver Operating Characteristic (ROC) curve. The area under the ROC curve (AUC) provides a metric for how well the overall model discriminates between the two target categories, with values $>.71$ indicating a large discriminatory effect $(d=.80$; Rice $\&$ Harris, 2005).

G*Power (Version 3.1; Faul, Erdfelder, Lang, \& Buchner, 2007; with at least 80\% power and $\alpha=.05$ ) indicated that 88 participants were required to conduct each $\chi^{2}$ and detect a medium effect (.30), and 102 participants were required to conduct each independent $t$ test and detect a medium effect (.50). Finally, Vittinghoff and McCulloch's (2007) simulation 
Running head: MENTALLY DISORDERED FIRESETTER RISK

study demonstrates that 10 participants for each IV (df) per outcome event is more than adequate for optimum model performance using binomial forced entry logistic regression.

\section{Results}

\section{Predictors of Firesetting Versus other Incident Types}

Univariate predictors of firesetting are shown in Table 1. For static factors, MDFs were differentiable from MDCs on their lower levels of substance use disorder and higher rates of previous psychiatric admission. There was also a trend towards MDFs being less likely to have a diagnosis of trauma/dissociative disorders relative to MDCs. MDFs and MDCs also differed on dynamic risk factors recorded one month prior to the incident. MDFs were more likely to express suicidal ideation/self-harm and be socially isolated in the month prior to the incident. However, relative to MDCs, MDFs were less likely to exhibit an external locus of control. There was also a trend towards MDFs having higher levels of impulsivity and lower levels of hostility relative to MDCs in the month prior to the incident. On general incident characteristics, MDFs were more likely to have targeted property and to have evidence of some premeditation of the incident relative to MDCs.

Entry of all significant univariate predictors and those trending towards significance into a logistic regression model showed that the model significantly improved upon chance prediction, $\chi^{2}(6)=39.71, p<.001$ (see Model 1, Table 2 for model parameters). The final model correctly classified $74 \%$ of participants (80\% of MDCs, $68 \%$ of MDFs). Only two outlier cases were identified through examination of standardised residuals, indicating no problems for model fit. A ROC curve calculated using the predicted probabilities for each case indicated that the model as a whole was very effective in discriminating between MDFs and MDCs $(\mathrm{AUC}=.80, p<.001)$. 
Running head: MENTALLY DISORDERED FIRESETTER RISK

\section{Gender Sensitive Differentiation of Firesetting Versus Other Incident Types}

Univariate analyses are shown in Table 1 . Among the 80 women, MDFs were less likely than MDCs to have the static risk factor of a diagnosis of substance use disorder and more likely to have previous hospital admissions. On dynamic risk factors recorded one month prior to the incident female MDFs were more likely to be observed isolating themselves and to demonstrate impulsivity relative to female MDCs. There was a trend towards female MDFs being more likely than female MDCs to demonstrate emotionalregulation deficits and express suicidal ideation/self-harm in the month prior to their incident. On general incident characteristics, female MDFs were more likely than their MDC counterparts to target property and to premeditate the incident.

For multivariate analyses, suicidal ideation/self-harm was removed due to multicollinearity with multiple other variables (i.e., impulsivity, emotional-regulation, and premeditation) and we removed impulsivity due to a significant moderate correlation with emotional-regulation. The final logistic regression model (see Model 2, Table 2) significantly improved upon chance classification, $\chi^{2}(5)=40.74, p<.001$, correctly classifying $80 \%$ of cases (86\% of MDCs, $75 \%$ of MDFs) and obtaining an AUC of .88 $(p<.001)$ in ROC analysis. Two cases were misclassified and obtained standardised residuals greater than 2, but this accounted for less than $5 \%$ of the sample suggesting model fit was adequate.

Among the 52 male participants, on static factors, MDFs were significantly more likely to have received a diagnosis for bipolar disorder and significantly less likely to have a diagnosis for substance use disorder. On dynamic risk factors recorded one month prior to the incident, male MDFs were significantly less likely than their male MDC counterparts to have exhibited hostility. For general incident characteristics, firesetting by male MDFs was more likely than control incidents to occur overnight and to target property. Due to small sample size and over-fitting, multivariate modelling was not possible for male participants. 
Running head: MENTALLY DISORDERED FIRESETTER RISK

\section{Differentiating Between Male and Female Firesetters}

Initial exploratory analyses showed that male and female MDFs were more similar than different across the variables and could only be differentiated on a small number of variables (see Table 3). On static factors, the 40 female MDFs were more likely than the 26 male MDFs to have received a diagnosis of a personality disorder. Further, on dynamic risk factors, female MDFs were more likely to have demonstrated problems with emotionalregulation and impulsivity in the month prior to the incident. On general incident characteristics, female MDFs were less likely to be intoxicated and more likely to target a person with their firesetting, which was typically themselves. There was also a trend for female MDFs to have experienced a triggering event in the month leading up to the incident relative to male MDFs.

Targeting self during the firesetting incident was highly correlated with setting a fire with the motivation of self-harm/suicide $(p=.76)$ and with targeting property $(p=-.94)$ so we removed this variable from subsequent analyses. Similarly, targeting property was strongly negatively correlated with setting fire with a motivation of self-harm/suicide $(p=-.70)$ leading the two variables to be tested independently in the final multivariate model. Overall, the combination of variables examining intoxication at the time of the incident, impulsivity in the month prior to the incident, and targeting property during the incident was best able to differentiate male and female MDFs (see Model 3, Table 2 for model parameters). This model correctly classified $81 \%$ of cases, although it was more accurate in classifying female MDFs than male MDFs (95\% vs. 58\%). Outlier analyses showed three men were incorrectly classified as women. Although this represented less than 5\% of the sample, it indicates some lack of fit. ROC analysis showed that the model effectively discriminated between male and female MDFs with an AUC of $.85(p<.001)$. Testing the same model but substituting 'targeting property' with the highly negatively correlated variable of 'fire as self- 
Running head: MENTALLY DISORDERED FIRESETTER RISK

harm/suicide' motive for setting the index fire was marginally less effective overall in classifying cases (79\% correct classification), but slightly more effective in correctly classifying male MDFs ( $88 \%$ female MDFs, $65 \%$ male MDFs).

\section{Differentiating One-time and Repeat MDFs}

Initial exploratory analyses showed a small number of differences between one-time $(N=$ 34) and repeat $(N=32)$ MDFs. Repeat MDFs were more likely to have the static risk factor of a diagnosis of personality disorder and the dynamic risk factors of being more likely to be assessed as demonstrating impulsivity and isolating themselves in the month prior to the index incident. However, they were less likely to have been non-compliant with prescribed medications in the month prior to the incident. On incident characteristics, repeat MDFs were also less likely to take steps to extinguish their fire. In addition, there were trends towards repeat MDFs being more likely to set multiple fires during their fire incident; being more often assessed as having an external locus of control; less likely to have been requesting help from services prior to the incident, and less likely to have had a recent change in care plan. While proportionally more women were repeat firesetters (53\% women vs. $42 \%$ men), there was no significant gender difference $\left(\chi^{2}(1)=.66, p=.42\right)$.

Entering these variables into an iterative process of logistic regression resulted in a final model including four variables (see Model 4, Table 2). This model produced classification significantly different from chance $\chi^{2}(4)=22.28, p<.001$ and correctly classified $71 \%$ of the sample $(72 \%$ repeat MDFs, $71 \%$ one-time MDFs). There were no outlier cases identified using this model. ROC curve calculation showed a good probability of differentiating between groups using this model ( $\mathrm{AUC}=.80, p<.001)$. 
Running head: MENTALLY DISORDERED FIRESETTER RISK

\section{Discussion}

This study is original and significant since it is the first to compare MDFs with a matched group of MDCs on potential static, dynamic, and incident-related risk factors. Overall, we found that mixed gender MDFs could be differentiated from MDC counterparts using a cluster of static, dynamic, and incident-related predictors (i.e., higher levels of previous hospital admissions, impulsivity, and incident premeditation, and lower levels of substance use disorder, hostility, and external locus of control). When risk predictor variables were examined separately for MDFs and MDCs subdivided by gender, we could only model risk predictors for females. Here, lower levels of substance misuse disorder diagnoses and higher levels of incident premeditation remained reliable predictors of female MDFs relative to female MDCs. However, emotional-regulation problems and social isolation in the month leading up to the incident uniquely predicted only female mentally disordered firesetting. Targeting property during the incident also predicted female MDFs versus female MDCs.

Previous research has highlighted that MDFs are characterised by a higher number of previous mental health service contacts or admissions relative to mentally disordered nonfiresetting offenders (Ducat et al., 2013). Impulsivity has also been identified as being prevalent within MDFs (Räsänen, Puumalainen, Janhonen, \& Väisänen, 1996). However, some of the mixed gender MDF predictors found in our study are somewhat new. For example, previous theoretical commentary—within the domain of firesetting more generally — has tended to portray firesetting as a form of learnt passive-aggressive hostility (see Gannon et al., 2012) and research (in the absence of adequate control groups) has reported substance dependence to be prevalent in a wide variety of firesetters (Grant \& Kim, 2007; Ritchie \& Huff, 1999). Our research—incorporating a matched control group — appears to challenge both assumptions since lower levels of substance misuse and hostility distinguished MDFs from their MDC counterparts. Nevertheless, it is possible that passive- 
Running head: MENTALLY DISORDERED FIRESETTER RISK

aggressive hostility was missed in our coding and that only overt hostility was coded. This may have resulted in exceptionally low levels of hostility being recorded for the firesetting group. Furthermore, no research has ever suggested that MDFs are more likely to premeditate an incident of firesetting relative to MDCs who commit other undesirable behaviours. This suggests a clear element of wilfulness to firesetting within psychiatric services.

Emotional-regulation problems have also been highlighted in MDFs and firesetters more generally (Geller, 1992; O’Sullivan \& Kelleher, 1989; Tyler \& Gannon, 2012). This static variable was a unique predictor of female firesetting - but was not associated with male firesetting - suggesting a clear gender difference. Given social isolation in the lead up to the firesetting was also a unique predictor for women, it is possible that they actively attempted to isolate themselves in order to plan their firesetting targeted at property. Alternatively, women may have premeditated their firesetting as a result of social isolation. In support of this latter hypothesis, research suggests that negative internal states, such as loneliness, can lead an individual to self soothe using fire, in an attempt to restore positive affect (Gannon et al., 2012; Ó Ciardha \& Gannon, 2012).

Interestingly, when we examined the best predictors of female MDFs versus male MDFs, these groups were clearly distinguishable using only three variables: intoxication, impulsivity, and targeting property during the incident. Female MDFs exhibited lower levels of intoxication during their firesetting, were more impulsive in the month leading up to their firesetting, and were less likely to set fire to property. A closer examination of the female MDFs' firesetting targets illustrated that they focused on a person as a target; typically themselves. These findings appear to support Dickens et al. (2007) who found female MDFs were more likely to set fires to attract attention or as a form of 'parasuicide' relative to male MDFs (see also Miller \& Fritzon , 2007) and that male MDFs were more likely than females to fireset whilst intoxicated. However, our findings also extend Dickens et al.'s through 
Running head: MENTALLY DISORDERED FIRESETTER RISK

suggesting that impulsive decision-making is particularly notable in female MDFs in the month leading up to their firesetting. Significant impulsivity issues are a key feature of borderline personality disorder and is more prevalent in female firesetters relative to males (see Ducat et al., 2017). Although borderline personality disorder was not highlighted separately in our study, it may explain why female MDFs targeted themselves when misusing fire. Our study extends previous findings through showing that many male MDFs appear to require a disinhibitor (i.e., intoxication) in order to misuse fire whereas females appear to hold internalised disinhibition (i.e., impulsivity).

Four key variables distinguished one-time and repeat MDFs. These variables spanned static and dynamic factors (i.e., personality disorder, medication non-compliance, external locus of control, and steps taken to extinguish the fire). In brief, repeat MDFs were likely to have a personality disorder diagnosis and to display an externalized locus of control in the lead up to their incident relative to one-time MDFs. Repeat MDFs were also less likely to have problems in medication compliance, or to take steps to extinguish the index fire. These results generally support the mainstream mentally disordered offending literature showing that recidivists demonstrate high levels of personality disorder (Coid, Hickey, Kahtan, Zhang, \& Yang, 2007; Walter, Wiesbeck, Dittmann \& Graf, 2011) and antisocial characteristics (Bonta, Blais, \& Wilson, 2014).

\section{Key Theoretical Contributions}

Our findings provide important theoretical contributions to the MDF literature. First, they suggest that individuals who misuse fire-relative to other mentally disordered offenders - hold a more pervasive mental health history characterised by repeated hospitalisations, general impulsivity, and premeditation in relation to firesetting. This provides support for the dynamic risk factor of coping and control proposed within the M- 
Running head: MENTALLY DISORDERED FIRESETTER RISK

TTAF. Not only does this research show that this factor can discriminate firesetters from their non-firesetting counterparts, but it also highlights the complexity of coping and control as a risk factor. MDFs appear to be hold both strengths and weaknesses in this domain; demonstrating impulsivity in the lead up to their fire incident but also some level of willfulness that would require self-governance to implement. Further, our findings show that although male and female MDFs have similar risk characteristics there are also key differences. For example, when specifically compared to male MDFs (Model 3), female MDFs were characterised by marked problems with emotion-regulation and impulsivity which appeared to have resulted in them being more likely to misuse fire towards individuals such as themselves. This supports the emotionally expressive subtype of the M-TTAF which proposes that women, in particular, hold problems with impulsivity that result in fire misuse as a form of 'cry for help', self-harm, or suicide (see also Long, Dickens, \& Dolley, 2014). Finally, our comparison of one-time and repeat firesetters (Model 4) highlighted that having a diagnosis of personality disorder, as well as an external locus of control, predicted repetitive fire use. This contributes to the M-TTAF through suggesting that these characteristics maintain firesetting in some way; perhaps via antisocial sentiments and cognitions (i.e., the Attitudes dynamic risk factor domain).

\section{Strengths, Limits, and Future Directions}

This study examined specialist archived NHS records obtained from clinical incident recording practices. This ensured that the data collected was ecologically grounded. We did, however, find that it was difficult to determine some key dynamic risk factors associated with mentally disordered firesetting because of this. For example, fire interest was not reliably measured or documented within patient files, and so we were unable to collect information on this dynamic risk variable. We also did not set out to examine whether MDFs who target self 
Running head: MENTALLY DISORDERED FIRESETTER RISK

or property differ in important ways. Future work might examine such differences to aid risk management within mental health care settings. Nevertheless, overall, our findings highlight the importance of examining male and female MDFs separately in future studies in order to develop gender-informed theoretical models of firesetting risk in mentally disordered firesetting. Our findings also highlight the importance of examining one-time versus repeat firesetters in order to further understand what drives persistent misuse of fire.

\section{Conclusion}

We found that numerous characteristics predict whether a mentally disordered individual has misused fire or engaged in some other undesirable behavior. Those who misused fire held more previous hospital admissions, exhibited impulsivity and incident premeditation as well as lower levels of substance use disorder, hostility, and external locus of control. When specifically examining females who had misused fire, relative to males, we found females were less likely to target property and held lower levels of intoxication during the incident. However, females exhibited more impulsivity. Finally we found those who had repeatedly misused fire were more likely to have a personality disorder and an external locus of control relative to one time offenders. Repeat offenders were also less likely to have medication compliance problems, or to try to extinguish their fire. 
Running head: MENTALLY DISORDERED FIRESETTER RISK

\section{References}

Bonta, J., Blais, J., \& Wilson, H. A. (2014). A theoretically informed meta-analysis of the risk for general and violent recidivism for mentally disordered offenders. Aggression and Violent Behavior, 19, 278-287. doi: 10.1016/j.avb.2014.04.014

Bradford, J. M. (1982). Arson: A clinical study. Canadian Journal of Psychiatry, 27, 188-193.

Brown, S., Bowen, E., \& Prescott, D. (2017). The forensic psychologist's report writing guide. NY: Routledge.

Coid, J., Hickey, N., Kahtan, N., Zhang, T., \& Yang, M. (2007). Patients discharged from medium secure forensic psychiatry services: reconvictions and risk factors. The British Journal of Psychiatry, 190, 223-229. doi:10.1192/bjp.bp.105.018788

Craig, L., Dixon, L., \& Gannon, T. A. (2012). What works in offender rehabilitation: An evidence-based approach to assessment and treatment. Chichester, UK: WileyBlackwell.

Dickens, G. L., \& Doyle, M. (2016). Mentally disordered firesetters in secure mental health care: A forensic mental health nursing perspective. In R. Doley, G. Dickens, \& T.A. Gannon (Eds), The psychology of arson: A practical guide to understanding and managing deliberate firesetters (pp.260-275). Abingdon, Oxon. Routledge.

Dickens, G., Sugarman, P., Ahmad, F., Edgar, S., Hofberg, K., \& Tewari, S. (2007). Gender differences amongst adult arsonists at psychiatric assessment. Medicine, Science, and the Law, 47, 233-238. doi:10.1258/rsmmsl.47.3.233

Dickens, G., Sugarman, P., Edgar. S., Hofberg, K., Tewari, S., \& Ahmad, F. (2009). Recidivism and dangerousness in arsonists. Journal of Forensic Psychiatry and Psychology, 20, 621-639. doi:10.1080/14789940903174006.

Douglas, K. S., Hart, S. D., Webster, C. D., \& Belfrage, H. (2013). HCR-20V3: Assessing risk of violence - User guide. Burnaby, Canada: Mental Health, Law, and Policy Institute, Simon Fraser University.

Ducat, L., McEwan, T., Ogloff, J., R., P. (2017). A comparison of psychopathology and reoffending in female and male convicted firesetters. Law and Human Behavior. doi: $10.1037 / \mathrm{lhb} 0000264$ 
Running head: MENTALLY DISORDERED FIRESETTER RISK

Ducat, L., Ogloff, J., R., P., \& McEwan, T. (2013). Mental illness and psychiatric treatment amongst firesetters, other offenders and the general community. Australian and New Zealand Journal of Psychiatry, 47, 945-953. doi:10.1177/0004867413492223

Enayati, J., Grann, M., Lubbe, S., \& Fazel, S. (2008). Psychiatric morbidity in arsonists referred for forensic psychiatric assessment in Sweden. Journal of Forensic Psychiatry and Psychology, 19, 139-147. doi:10.1080/14789940701789500

Faul, F., Erdfelder, E., Lang, A. G., \& Buchner, A. (2007). G*Power 3: A flexible statistical power analysis program for the social, behavioral, and biomedical sciences. Behavior Research Methods, 39, 175-191. doi:10.3758/bf03193146

Gannon, T. A., Ó Ciardha, C., Barnoux, M. F., Tyler, N., Mozova, K., \& Alleyne, E. (2013) Male imprisoned firesetters have different characteristics than other imprisoned offenders and require specialist treatment. Psychiatry: Interpersonal and Biological Processes, 76, 349-64. doi:10.1521/psyc.2013.76.4.349

Gannon, T. A., Ó Ciardha, C., Doley, R, M., \& Alleyne, E. (2012). The Multi Trajectory Theory of Adult Firesetting (M-TTAF). Aggression and Violent Behaviour, 17, 107-121. doi:10.1016/j.avb.2011.08.001

Geller, J. L. (1992). Communicative arson. Journal of Hospital and Community Psychiatry, 43. 76-77.

Geller, J. L., Fisher, W. H., Moynihan, K. (1992). Adult lifetime prevalence of firesetting behaviors in a state hospital population. Psychiatric Quarterly, 63, 129-142. doi:10.1007/bf01065986

Grant, J. E., \& Kim. S. W. (2007). Clinical characteristics and psychiatric comorbidity of pyromania. Journal of Clinical Psychiatry, 68, 1717-1722. doi:10.4088/jcp.v68n1111

Hagenauw, L. A., Karsten, J., Akkerman-Bouwsema, G. J., de Jager, B. E., \& Lancel, M. (2014). Specific risk factors of arsonists in a forensic psychiatric hospital. International Journal of Offender Therapy and Comparative Criminology, 58, 116. doi:10.1177/0306624X13519744

Hart, S., Sturmey, P., Logan, C., \& McMurran, M. (2011). Forensic case formulation. International Journal of Forensic Mental Health, 10. 118-126. doi:10.1080/14999013.2011.577137

Labree, W., Mijman, H., van Marle, H., \& Rassin, E. (2010). Backgrounds and characteristics of arsonists. International Journal of Law and Psychiatry, 33, 149153. doi:10.1016/j.ijlp.2010.03.004

Long, C. G., Dickens, G., \& Dolley, O. (2014). Features and motivators of emotionally 
Running head: MENTALLY DISORDERED FIRESETTER RISK

expressive firesetters: the assessment of women in secure psychiatric settings. Journal of Criminal Psychology, 4, 129 - 142. doi:10.1108/JCP-08-2013-0022

Long, C. G., Fitzgerald, K., \& Hollin, C. R. (2015). Women firesetters admitted to secure psychiatric services: Characteristics and treatment needs. Victims \& Offenders: An International Journal of Evidence-based Research, Policy, and Practice, 10, 341353. doi:10.1080/15564886.2014.967901

McEwan, T. E., Doley, R. M., \& Dolan, M. (2012). Bushfire and wildfire arson: Arson risk assessment in the Australian context. In G. L. Dickens, T. A. Gannon \& P. A. Sugarman (Eds), Firesetting and mental health (pp. 206-223). London: Royal College of Psychiatrists.

Miller, S., \& Fritzon, K. (2007). Functional consistency across two behavioural modalities: fire-setting and self-harm in female special hospital patients. Criminal Behaviour and Mental Health, 17, 31-44. doi:10.1002/cbm.637

Ó Ciardha, C., \& Gannon, T. A. (2012). The implicit theories of firesetters: A preliminary conceptualization. Aggression and Violent Behavior, 17, 122-128. doi:10.1016/j.avb. 2011.12.001

O’Sullivan, G., \& Kelleher, M. J. (1989). Intentional self burning by psychiatric patients. Irish Journal of Psychological Medicine, 6, 41-43. doi:10.1017/s079096670001572

Räsänen, P., Hakko, H., \& Väisänen, E. (1995). The mental state of arsonists as determined by forensic psychiatric examinations. The Bulletin of the American Academy of Psychiatry and the Law, 23, 547-553.

Räsänen, P., Puumalainen, T., Janhonen, S., \& Väisänen, E. (1996). Firesetting from the viewpoint of an arsonist. Journal of Psychosocial Nursing, 34, 16-21. doi:10.1016/0379-0738(95)01710-0

Repo, E., Virkkunen, M., Rawlings, R., \& Linnoila, M. (1997). Criminal and psychiatric histories of Finnish arsonists. Acta Scandinavica, 95, 318-323.doi:10.1111/j.16000447.1997.tb09638x

Rice, M. E., \& Harris, G. T. (1991). Firesetters admitted to a maximum security psychiatric institution. Journal of Interpersonal Violence, 33, 461-475. doi: $10.1177 / 088626091006004005$

Rice, M. E., \& Harris, G. T. (1996). Predicting the recidivism of mentally disordered firesetters. Journal of Interpersonal Violence, 11, 364-375. doi:10.1177/088626096011003004

Rice, M. E., \& Harris, G. T. (2005). Comparing effect sizes in follow-up studies: ROC Area, 
Running head: MENTALLY DISORDERED FIRESETTER RISK

Cohen's $d$, and r. Law and Human Behavior, 29, 615-620. doi:10.1007/s10979-005$6832-7$

Ritchie, E. C., \& Huff, T. G. (1999). Psychiatric aspects of arsonists. Journal of Forensic Sciences, 44, 733-740. doi:10.1520/jfs 14546j

Tyler, N., \& Gannon, T. A. (2012). Explanations of firesetting in mentally disordered offenders: A review of the literature. Psychiatry: Interpersonal and Biological Processes, 75, 150-166. doi:10.1521/psyc.2012.75.2.150

Tyler, N., Gannon, T. A., Dickens, G. L., \& Lockerbie, L. (2015). Characteristics that predict firesetting in male and female mentally disordered offenders. Psychology, Crime \& Law, 21, 776-797. doi: 10.1080/1068316X.2015.1054382

Vittinghoff, E., \& McCulloch, C. E. (2007). Relaxing the rule of ten events per variable in logistic and cox regression. American Journal of Epidemiology, 165, 710-718. doi:10.1093/aje/kwk052

Walter, M., Wiesbeck, G. A., Dittmann, V., \& Graf, M. (2011). Criminal recidivism in offenders with personality disorders and substance use disorders over 8 years of time at risk. Psychiatry Research, 186 (2-3). 443-445. doi:

10.1016/j.psychres.2010.08.009. 
Running head: MENTALLY DISORDERED FIRESETTER RISK

Table 1

Univariate Predictors of Firesetting Incidents

\begin{tabular}{|c|c|c|c|c|c|c|}
\hline Variable & $\begin{array}{c}\text { Whole Sample } \\
(N=132) \\
\% \mathrm{MDC}, \% \mathrm{MDF}\end{array}$ & $\chi^{2}, p$ & $\begin{array}{c}\text { Females } \\
(N=80) \\
\% \mathrm{MDC}, \% \mathrm{MDF}\end{array}$ & $\chi^{2}, p$ & $\begin{array}{c}\text { Males } \\
(N=52) \\
\% \mathrm{MDC}, \% \mathrm{MDF}\end{array}$ & $\chi^{2}, p$ \\
\hline \multicolumn{7}{|l|}{ Static Factors } \\
\hline \multicolumn{7}{|l|}{ Marital Status } \\
\hline Single or Divorced & $74.2,84.8$ & $2.28, .13$ & $72.5,82.5$ & $1.15, .28$ & $76.9,88.5$ & $.47^{\mathrm{a}}$ \\
\hline Ethnicity (white) & $92.4,93.9$ & $1.0^{\mathrm{a}}$ & $95.0,95.0$ & $1.0^{\mathrm{a}}$ & $88.5,92.3$ & $1.0^{\mathrm{a}}$ \\
\hline \multicolumn{7}{|l|}{ Psychiatric Diagnoses } \\
\hline Anxiety & $4.5,1.5$ & $.62^{\mathrm{a}}$ & $7.5,2.5$ & $.62^{\mathrm{a}}$ & $0.0,0.0$ & - \\
\hline Personality Disorder & $43.9,50.0$ & $49, .49$ & $45.0,60.0$ & $1.81, .18$ & $42.3,34.6$ & $.33, .57$ \\
\hline Bipolar Disorder & $13.6,21.2$ & $1.32, .25$ & $20.0,15.0$ & $.35, .56$ & $3.8,30.8$ & $.02^{\mathrm{a}}$ \\
\hline Depressive Disorder & $6.1,10.6$ & $.89, .35$ & $10.0,10.0$ & $.00,1.00$ & $0.0,11.5$ & $.24^{\mathrm{a}}$ \\
\hline Trauma/dissociative Disorder & $21.2,9.1$ & $3.77, .05$ & $17.5,7.5$ & $1.83, .18$ & $26.9,11.5$ & $1.98, .16$ \\
\hline Substance Use Disorder & $54.5,19.7$ & $17.17,<.001$ & $45.0,17.5$ & $7.04, .01$ & 69.2, 23.1 & $11.1,<.001$ \\
\hline Psychotic Disorder & $50.0,54.5$ & $.27, .60$ & $42.5,52.5$ & $.80, .37$ & $61.5,57.7$ & $.08, .78$ \\
\hline Neurological Disorder & $25.8,16.7$ & $1.63, .20$ & $30.0,22.5$ & $.58, .45$ & $19.2,7.7$ & $.42^{\mathrm{a}}$ \\
\hline Previous Hospital Admission & 69.784 .8 & $4.31, .04$ & $70.0,90.0$ & $5.0, .03$ & $69.2,76.9$ & $.39, .53$ \\
\hline \multicolumn{7}{|l|}{ Dynamic Factors $^{b}$} \\
\hline Active MI Symptoms & $77.3,81.8$ & $.42, .52$ & $82.5,82.5$ & $.00,1.00$ & $69.2,80.8$ & $.92, .34$ \\
\hline Change in Care Plan & $36.4,33.3$ & $.13, .72$ & $37.5,32.5$ & $.22, .64$ & $34.6,34.6$ & $.00,1.00$ \\
\hline Dependency on Others & $9.1,10.6$ & $.09, .77$ & $15.0,10.0$ & $.46, .50$ & $0.0,11.5$ & $24^{\mathrm{a}}$ \\
\hline Emotional-regulation Problems & $62.1,71.2$ & $1.23, .27$ & $62.5,82.5$ & 4.01, .05 & $61.5,53.8$ & $.32, .58$ \\
\hline External Locus of Control & $24.2,10.6$ & $4.27, .04$ & $22.5,12.5$ & $1.39, .24$ & $26.9,7.7$ & $.14^{\mathrm{a}}$ \\
\hline Impulsivity & $59.1,74.2$ & $3.41, .07$ & $65.0,87.5$ & $5.59, .02$ & $50.0,53.8$ & $.08, .78$ \\
\hline Hostility & $84.8,71.2$ & $3.58, .06$ & $75.0,72.5$ & $.07, .80$ & $100,69.2$ & $<.001^{\mathrm{a}}$ \\
\hline Medication Non-compliance & $40.9,43.9$ & $.12, .73$ & $42.5,40.0$ & $.05, .82$ & $38.5,50.0$ & $.70, .40$ \\
\hline Mood Fluctuation & $9.1,7.6$ & $.10, .75$ & $12.5,10.0$ & $1.00^{\mathrm{a}}$ & $3.8,3.8$ & $1.00^{\mathrm{a}}$ \\
\hline Poor Physical Health & $18.2,19.7$ & $.05, .82$ & $25.0,17.0$ & $67, .41$ & $7.7,23.1$ & $.25^{\mathrm{a}}$ \\
\hline Poor Self Care & $54.5,60.6$ & $.49, .48$ & $52.5,55.0$ & $.05, .82$ & $57.7,69.2$ & $.75, .39$ \\
\hline Relationship Problems & $37.9,47.0$ & $1.12, .29$ & $35.0,52.5$ & $2.49, .12$ & $42.3,38.5$ & $.08, .78$ \\
\hline Requests Help from Services & $13.6,18.2$ & $.51, .48$ & $12.5,12.5$ & $.00,1.00$ & $15.4,26.9$ & $1.04, .31$ \\
\hline
\end{tabular}


Running head: MENTALLY DISORDERED FIRESETTER RISK

\begin{tabular}{|c|c|c|c|c|c|c|}
\hline Social Isolation & $19.7,36.4$ & $4.54, .03$ & $10.0,40.0$ & $9.6,<.001$ & $34.6,30.8$ & $.09, .77$ \\
\hline Substance Misuse & $31.8,39.4$ & $.83, .36$ & $25.0,32.5$ & $55, .46$ & $42.3,50.0$ & $.31, .58$ \\
\hline Suicidal Ideation/Self-Harm & $45.5,63.6$ & $4.40, .04$ & $50.0,70.0$ & $.33, .07$ & $38.5,53.8$ & $1.24, .27$ \\
\hline Treatment Disengagement & $47.0,40.9$ & $.49, .48$ & $47.5,37.5$ & $.82, .37$ & $46.2,46.2$ & $.00,1.00$ \\
\hline Triggering Event & $53.0,43.9$ & $1.09, .30$ & $62.5,52.5$ & $.82, .37$ & $38.5,30.8$ & $34, .56$ \\
\hline \multicolumn{7}{|l|}{ Incident Characteristics - General } \\
\hline Incident Occurred at Night ${ }^{(10 \mathrm{pm}-6 \mathrm{am})}$ & $28.8,42.4$ & $2.68, .10$ & $35.0,40.0$ & $.21, .64$ & $19.2,46.2$ & $4.28, .04$ \\
\hline Intoxication & $19.7,22.7$ & $.18, .67$ & $17.5,10.0$ & $.95, .33$ & $23.1,42.3$ & $2.19, .14$ \\
\hline Targeted Property & $8.3,53.0$ & $28.98,<.001$ & $5.7,37.5$ & $10.76,<.001$ & $12.0,76.9$ & $21.7,<.001$ \\
\hline Threats Prior to Incident & $27.3,25.8$ & $.04, .84$ & $25.0,30.0$ & $.25, .62$ & $30.8,19.2$ & $.92, .34$ \\
\hline Premeditation & $34.8,60.6$ & $8.78,<.001$ & $30.0,62.5$ & $8.50,<.001$ & $42.3,57.7$ & $1.23, .27$ \\
\hline
\end{tabular}

Note. boldface indicates variables significant at $p<.05$ or trending towards significance at this level. ${ }^{\mathrm{a}}$ indicates Fisher's Exact Test; ${ }^{\mathrm{b}}$ indicates measurement one month prior to the incident. 
Running head: MENTALLY DISORDERED FIRESETTER RISK

Table 2

Best Final Differentiating Logistic Regression Models

\begin{tabular}{|c|c|c|c|c|c|c|}
\hline & $\beta$ & Wald & $p$ & OR & $95 \%$ & or OR \\
\hline & & & & & Lower & Upper \\
\hline \multicolumn{7}{|l|}{ Model $1(N=132)$} \\
\hline Premeditation & 1.17 & 8.05 & .01 & 3.22 & 1.44 & 7.21 \\
\hline Substance Use Disorder & -1.70 & 15.00 & $<.001$ & .18 & .08 & .43 \\
\hline Impulsivity & .99 & 4.86 & .03 & 2.69 & 1.12 & 6.49 \\
\hline Hostility & -.86 & 3.03 & .08 & .42 & .16 & 1.12 \\
\hline External Locus of Control & -.90 & 2.58 & .11 & .41 & .14 & 1.22 \\
\hline Previous Hospital Admissions & .86 & 3.01 & .08 & 2.37 & .89 & 6.29 \\
\hline \multicolumn{7}{|l|}{ HL goodness of fit: $\chi^{2}(7)=3.90, p=.79$} \\
\hline \multicolumn{7}{|l|}{ Model $2(N=80)$} \\
\hline Premeditation & 2.01 & 7.40 & .01 & 7.63 & 1.76 & 32.97 \\
\hline Substance Use Disorder & -2.10 & 6.73 & .01 & .12 & .03 & .60 \\
\hline Emotion-regulation & 1.73 & 4.24 & .04 & 5.67 & 1.09 & 29.52 \\
\hline Social Isolation & 1.61 & 4.32 & .04 & 4.99 & 1.10 & 22.72 \\
\hline Property Target & 2.63 & 5.86 & .02 & 13.81 & 1.65 & 115.70 \\
\hline \multicolumn{7}{|l|}{ HL goodness of fit: $\chi^{2}(6)=1.42, p=.97$} \\
\hline \multicolumn{7}{|l|}{ Model $3(N=66)$} \\
\hline \multicolumn{7}{|l|}{ Male MDFs vs. Female MDFs* } \\
\hline Intoxication & -1.86 & 5.55 & .02 & .16 & .03 & .73 \\
\hline Impulsivity & 2.42 & 8.81 & .01 & 11.25 & 2.28 & 55.58 \\
\hline Property Target & -2.03 & 7.80 & .01 & .13 & .03 & .54 \\
\hline \multicolumn{7}{|l|}{ HL goodness of fit: $\chi^{2}(4)=2.30, p=.68$} \\
\hline \multirow{2}{*}{\multicolumn{7}{|c|}{$\begin{array}{c}\text { Model 4 }(N=66) \\
\text { One-time MDFs vs. Repeat MDFs }{ }^{\circ}\end{array}$}} \\
\hline & & & & & & \\
\hline Personality Disorder & 1.28 & 4.54 & .03 & 3.58 & 1.11 & 11.56 \\
\hline Steps Taken to Extinguish Fire & -2.06 & 5.17 & .02 & .13 & .02 & .75 \\
\hline Medication Non-compliance & -1.44 & 5.71 & .02 & .24 & .07 & .78 \\
\hline External Locus of Control & 2.76 & 3.36 & .07 & 15.73 & .83 & 300.0 \\
\hline HL goodness of fit: $\chi^{2}(5)=2.75, p=.74$ & & & & & & \\
\hline
\end{tabular}

Note. ${ }^{*}$ Female gender is coded as presence of outcome in Model $3 ;^{\circ}$ Repeat firesetting is coded as presence of outcome in Model 4. 
Running head: MENTALLY DISORDERED FIRESETTER RISK

Table 3.

Univariate Predictors differentiating between sub-sets of mentally disordered firesetters

\begin{tabular}{|c|c|c|c|c|c|c|}
\hline Variable & $\begin{array}{c}\% \text { Females } \\
(N=40)\end{array}$ & $\begin{array}{l}\text { \% Males } \\
(N=26)\end{array}$ & $\chi^{2}, p$ & $\begin{array}{c}\text { \% One-Time } \\
(N=34)\end{array}$ & $\begin{array}{l}\% \text { Repeat } \\
(N=32)\end{array}$ & $\chi^{2}, p$ \\
\hline \multicolumn{7}{|l|}{ Static Factors } \\
\hline Gender (female) & - & - & - & 55.9 & 65.6 & $.66, .42$ \\
\hline \multicolumn{7}{|l|}{ Marital Status } \\
\hline Single or Divorced & 82.5 & 88.5 & $.73^{\mathrm{a}}$ & 88.2 & 81.3 & $.51^{\mathrm{a}}$ \\
\hline Ethnicity (white) & 95.0 & 92.3 & $.64^{\mathrm{a}}$ & 91.2 & 96.9 & $.61^{\mathrm{a}}$ \\
\hline \multicolumn{7}{|l|}{ Diagnoses } \\
\hline Personality Disorder & 60.0 & 34.6 & $4.06, .04$ & 35.3 & 65.6 & $6.01, .01$ \\
\hline Bipolar Disorder & 15.0 & 30.8 & $2.35, .13$ & 20.6 & 21.9 & $.02, .90$ \\
\hline Depressive Disorder & 10.0 & 11.5 & $1.0^{\mathrm{a}}$ & 11.8 & 9.4 & $1.0^{\mathrm{a}}$ \\
\hline Trauma/dissociative Disorder & 7.5 & 11.5 & $.67^{\mathrm{a}}$ & 11.8 & 6.3 & $.67^{\mathrm{a}}$ \\
\hline Substance Disorder & 17.5 & 23.1 & $.31, .58$ & 11.8 & 28.1 & $2.79, .10$ \\
\hline Psychotic Disorder & 52.5 & 57.7 & $.17, .68$ & 55.9 & 53.1 & $.05, .82$ \\
\hline Neurological Disorder & 22.5 & 7.7 & $.18^{\mathrm{a}}$ & 17.6 & 15.6 & $.05, .83$ \\
\hline Previous Hospital Admission & 90 & 76.9 & $.18^{\mathrm{a}}$ & 82.4 & 87.5 & $.73^{\mathrm{a}}$ \\
\hline \multicolumn{7}{|l|}{ Dynamic Factors $^{\text {b }}$} \\
\hline Active MI Symptoms & 82.5 & 80.8 & $1.0^{\mathrm{a}}$ & 79.4 & 84.4 & $.27, .60$ \\
\hline Change in Care Plan & 32.5 & 34.6 & $.03, .86$ & 23.5 & 43.8 & $3.03, .08$ \\
\hline Dependency on Others & 10.0 & 11.5 & $1.0^{\mathrm{a}}$ & 17.6 & 3.1 & $.11^{\mathrm{a}}$ \\
\hline Emotional-regulation Problems & 82.5 & 53.8 & $6.31, .01$ & 64.7 & 78.1 & $1.45, .23$ \\
\hline External Locus of Control & 12.5 & 7.7 & $.70^{\mathrm{a}}$ & 2.9 & 18.8 & $.05^{a}$ \\
\hline Impulsivity & 87.5 & 53.8 & $9.33,<.01$ & 61.8 & 87.5 & $5.71, .02$ \\
\hline Hostility & 72.5 & 69.2 & $.08, .77$ & 64.7 & 78.1 & $1.45, .23$ \\
\hline Medication Non-compliance & 40.0 & 50.0 & $.64, .42$ & 58.8 & 28.1 & $6.31, .01$ \\
\hline Poor Physical Health & 17.5 & 23.1 & $.31, .58$ & 23.5 & 15.3 & $.65, .42$ \\
\hline Poor Self Care & 55.0 & 69.2 & $1.34, .25$ & 61.8 & 59.4 & $.04, .84$ \\
\hline Relationship Problems & 52.5 & 38.5 & $1.25, .26$ & 44.1 & 50.0 & $.23, .63$ \\
\hline Requests Help from Services & 12.5 & 26.9 & $.19^{\mathrm{a}}$ & 26.5 & 9.4 & $3.23, .07$ \\
\hline Social Isolation & 40.0 & 30.8 & $.58, .45$ & 23.5 & 50.0 & $4.99, .03$ \\
\hline Substance Misuse & 32.5 & 50.0 & $2.02, .16$ & 41.2 & 37.5 & $.09, .76$ \\
\hline
\end{tabular}


Running head: MENTALLY DISORDERED FIRESETTER RISK

\begin{tabular}{|c|c|c|c|c|c|c|}
\hline Suicidal Ideation/Self-Harm & 70.0 & 53.8 & $1.78, .18$ & 58.8 & 68.8 & $.70, .40$ \\
\hline Triggering Event & 52.5 & 30.8 & $3.02, .08$ & 44.1 & 43.8 & $.00, .98$ \\
\hline \multicolumn{7}{|l|}{ Incident Characteristics - General } \\
\hline Incident Occurred at Night ${ }^{(10 \mathrm{pm}-6 \mathrm{am})}$ & 40.0 & 46.2 & $.24, .62$ & 38.2 & 46.9 & $.50, .48$ \\
\hline Threats Prior to Incident & 30.0 & 19.2 & $.96, .33$ & 17.6 & 34.4 & $2.41, .12$ \\
\hline Premeditation & 62.5 & 57.7 & $.15, .70$ & 55.9 & 65.6 & $.66, .42$ \\
\hline Property & 37.5 & 76.9 & $9.83,<.01$ & 50.0 & 56.3 & $.26, .61$ \\
\hline Person & 62.5 & 23.1 & As above ${ }^{c}$ & 50.0 & 43.8 & As above ${ }^{c}$ \\
\hline Fire Target was Self & $\mathbf{5 7 . 5}$ & 23.1 & $7.58, .01$ & 44.1 & 43.8 & $.00, .98$ \\
\hline \multicolumn{7}{|l|}{ Fire Location } \\
\hline Hospital Bedroom & 30.8 & 42.3 & $4.35, .23$ & 24.8 & 46.9 & $5.50, .14$ \\
\hline Community & 25.6 & 38.5 & As above ${ }^{c}$ & 42.5 & 18.8 & As above ${ }^{c}$ \\
\hline Fire as Self-harm/Suicide & 57.5 & 30.8 & $4.52, .03$ & 44.1 & 50.0 & $.23, .63$ \\
\hline Multiple Ignition Points & 5.0 & 15.4 & $.20^{\mathrm{a}}$ & 8.8 & 9.4 & $1.00^{\mathrm{a}}$ \\
\hline Spate Firesetting & 15 & 11.5 & $1.0^{\mathrm{a}}$ & 5.9 & 21.9 & $.08^{\mathrm{a}}$ \\
\hline
\end{tabular}

Note. Boldface indicates variables significant at $p<.05$ or trending towards significance at this level. ${ }^{\text {a }}$ indicates Fisher's Exact Test; ${ }^{\mathrm{b}}$ indicates measurement one month prior to the incident; ${ }^{\mathrm{c}}=$ single multi-category analysis of frequencies differences used. 